CLINICAL STUDY

\title{
Assessing 1-h plasma glucose and shape of the glucose curve during oral glucose tolerance test
}

\author{
Weibin Zhou, Yanyun Gu, Hong Li and Min Luo \\ Department of Endocrinology, Shanghai Institute of Endocrine and Metabolic Diseases, Ruijin Hospital, Shanghai Jiaotong University School of Medicine \\ (SJU-SM, formerly Shanghai Second Medical University), 197, Ruijin 2nd Road, Shanghai 200025, China
}

(Correspondence should be addressed to M Luo; Email: pdsucs@126.com)

\begin{abstract}
Objective: To assess the cutoff values at different time points for impaired glucose regulation (IGR) and diabetes, the glucose curve and isolated 1-h hyperglycemia were monitored during an oral glucose tolerance test (OGTT).

Methods: Two thousand eight hundred and eighty-six subjects (1300 men and 1586 women) were recruited to have an OGTT. Plasma was collected at $0,30,60,120$, and $180 \mathrm{~min}$ to analyze glucose and insulin. The diagnosis of impaired fasting glucose, impaired glucose tolerance, and diabetes was based on World Health Organization and American Diabetes Association's criteria. Those with fasting plasma glucose $(\mathrm{FPG})<5.6$ and 2 -h plasma glucose $(\mathrm{PG})<7.8$, but $1-\mathrm{h} \mathrm{PG} \geq 7.8$ and $<11.1 \mathrm{mmol} / \mathrm{l}$ were defined as 1 h-High7.8, and those with FPG $<7.0$ and $2-\mathrm{h} \mathrm{PG}<11.1$, but 1 -h $\mathrm{PG} \geq 11.1 \mathrm{mmol} / \mathrm{l}$ as 1h-High11.1. The cutoff values were calculated by receiver operating characteristic (ROC) curve. The correlation between $\beta$-cell function and the area under the curve of glucose (AUCg) and the shape index was analyzed with linear regression.

Results: The cutoff values for IGR were 5.6, 9.7, 10.1, 7.8 and $6.1 \mathrm{mmol} / \mathrm{l}$ for blood glucose at 0,30 , 60,120 and $180 \mathrm{~min}, 24$ for AUCg and $1.3 \mathrm{mmol} / \mathrm{l}$ for the shape index. The cutoff values for diabetes were $6.8,11.2,13,11.1$ and $7 \mathrm{mmol} / \mathrm{l}$ for $0,30,60,120$ and $180 \mathrm{~min}, 30.9$ for AUCg and $2 \mathrm{mmol} / \mathrm{l}$ for the shape index. Both $\mathrm{AUCg}$ and the shape index were inversely related to $\beta$-cell function. The profiles of glucose and insulin in the subgroup with isolated 1-h hyperglycemia were very different from those seen in subjects with normal glucose tolerance or IGR.

Conclusions: The present study provides new information on measures other than the fasting and 2-h PG to evaluate glucose metabolism in vivo and stimulates further research aimed at assessing the value of the OGTT 1-h PG concentration prospectively.
\end{abstract}

European Journal of Endocrinology 155 191-197

\section{Introduction}

Among all diabetes, type 2 diabetes accounts for $90-95 \%$. This form of diabetes frequently goes undiagnosed for many years, because hyperglycemia develops gradually. Early detection, diagnosis, and early treatment of diabetes are very important for preventing diabetic complications and reducing the costs of medical care. Although fasting plasma glucose (FPG) alone does not always detect people with impaired glucose tolerance (IGT) and the 2-h plasma glucose (PG) does not always identify people with impaired fasting glucose (IFG), both tests are useful in terms of their ability to detect hyperglycemia and the consequences of disordered glucose metabolism. The new term 'pre-diabetes' or impaired glucose regulation (IGR) was introduced recently and refers to patients with IFG and/or IGT. The oral glucose tolerance test (OGTT) offers the obvious advantage that both FPG and 2-h PG are measured. Therefore, the World Health Organization (WHO) continues to recommend the OGTT in screening for diabetes (1), while endorsing the new diabetic FPG threshold of $\geq 7.0 \mathrm{mmol} / \mathrm{l}$, following the publication of the American Diabetes Association (ADA) criteria.

The OGTT has traditionally been used to classify the status of glucose tolerance for diagnostic purposes: normal glucose tolerance (NGT), IGT and diabetes (2) based on the 2-h PG concentration. The ADA lowered the threshold for IFG from $6.1 \mathrm{mmol} / \mathrm{l}$ to 5.6 in order to detect more subjects with pre-diabetes (3). However, the information provided at different time points other than at $2 \mathrm{~h}$ during OGTT seems to attract little attention. When we consider these values, we have to ask what the reference cutoff values are that correlate with FPG and 2-h PG values used for the diagnosis of IGT and diabetes. To the best of our knowledge, no one except us (4) has discussed the cutoff values for IGR at the time points of 30, 60, and $180 \mathrm{~min}$ during OGTT. Here, we tried to demonstrate the significance of the cutoff values at different time points and the area under the curve of 
glucose (AUCg) during OGTT for discrimination of various degrees of glucose tolerance.

The OGTT also determines the shape of the PG curve based on the measurements at $0,30,60,120$, and $180 \mathrm{~min}$. We could, however, identify only two studies which have addressed this issue. One study classified the glucose curve as 'biphasic', 'domed', and 'upward' (5), while the other study categorized the glucose curve as 'monophasic', 'biphasic', and 'unclassified' (6). These studies suggest that the shape harbors metabolic information not captured by the level of glycemia alone. However, neither of them has discussed the diagnostic function of the shape of the curve. In the present study, we made an attempt to extract metabolic information from the shape of the PG curve during an OGTT. The correlation between AUCg, shape index, and $\beta$-cell function was also analyzed.

As far as we are aware, we are the first to propose the concept of isolated 1-h hyperglycemia defined as $1 \mathrm{~h}$ High7.8 and 1h-High11.1 and to describe their characteristics. The intention is to assess whether it is possible to identify more pre-diabetic subjects before they fall into the criteria of WHO and ADA.

\section{Subjects and methods}

\section{Subjects}

Two thousand eight hundred and eighty-six Chinese subjects (1300 men and 1586 women), aged $46 \pm 16$ years old, referred to the Department of Endocrinology, Ruijin Hospital with endocrinological and metabolic disorders or physical check-up to have an OGTT were recruited from March 2004 to December 2005. Informed consent was obtained from all subjects.

\section{Measurements}

Anthropometric measurements included height, weight, body mass index (BMI; $\mathrm{kg} / \mathrm{m}^{2}$ ), waist to hip ratio and systolic/diastolic blood pressure. Standing height $(\mathrm{cm})$ and weight $(\mathrm{kg})$ were measured without shoes in light clothing. Blood pressure was measured in the right arm.

\section{OGTT}

OGTT was performed according to the WHO standard (1). After a 10-h overnight fast, the study subjects ingested a solution containing $75 \mathrm{~g}$ of anhydrous glucose, and venous blood samples were collected at 0 , $30,60,120$, and 180 min for determination of PG and insulin. PG was assayed by an automated glucose oxidase method. Insulin was determined by RIA (DSL1600, Diagnostic Systems Laboratories, Inc., Webster, TX, USA), the intra- and interassays coefficients of variation were 6.4 and $8.9 \%$ respectively. During the test, subjects remained at rest, seated or lying, and refrained from drinking or smoking. All measurements were done in the same laboratory.

\section{Diagnosis and classification}

NGT was defined as FPG $<5.6 \mathrm{mmol} / \mathrm{l}(100 \mathrm{mg} / \mathrm{dl})$ and $2-\mathrm{h} \quad \mathrm{PG}<7.8 \mathrm{mmol} / \mathrm{l} \quad(140 \mathrm{mg} / \mathrm{dl})$, IFG as FPG $\geq 5.6 \mathrm{mmol} / \mathrm{l} \quad(100 \mathrm{mg} / \mathrm{dl})$ and $<7.0 \mathrm{mmol} / \mathrm{l}$ $(126 \mathrm{mg} / \mathrm{dl}), \quad$ IGT as $\quad 2-\mathrm{h} \quad \mathrm{PG} \geq 7.8 \mathrm{mmol} / \mathrm{l}$ $(140 \mathrm{mg} / \mathrm{dl})$ and $<11.1 \mathrm{mmol} / \mathrm{l}(200 \mathrm{mg} / \mathrm{dl})$ (2). IFG and IGT classifications were assigned independently; therefore, subjects with IFG may or may not have IGT. Subjects were provisionally classified as having diabetes if any of these criteria met: $F P G \geq 7.0 \mathrm{mmol} / \mathrm{l}$ (126 mg/dl), 2-h glucose $\geq 11.1 \mathrm{mmol} / \mathrm{l}(200 \mathrm{mg} / \mathrm{dl})$, or reported use of antihyperglycemic medication prescribed for the management of diabetes by a physician (2). We defined provisionally those whose FPG $<5.6 \mathrm{mmol} / \mathrm{l}$ and 2 - $\mathrm{h} \mathrm{PG}<7.8 \mathrm{mmol} / \mathrm{l}$, but 1 -h $\mathrm{PG} \geq 7.8 \mathrm{mmol} / \mathrm{l}$ and $<11.1 \mathrm{mmol} / \mathrm{l}$ as $1 \mathrm{~h}-H i g h 7.8$, and those whose FPG $<7.0 \mathrm{mmol} / \mathrm{l}$ and $2-\mathrm{h}$ PG $<$ $11.1 \mathrm{mmol} / \mathrm{l}$, but $1-\mathrm{h} \quad \mathrm{PG} \geq 11.1 \mathrm{mmol} / \mathrm{l}$ as $1 \mathrm{~h}$ High11.1. Subgroups of 1h-High7.8 and $1 \mathrm{~h}$ High11.1 were separated from NGT and IGR. When 1h-High7.8 and 1h-High11.1 were analyzed, there were no duplicate classification in NGT and IGR.

\section{Calculations and statistical analysis}

The AUCg during OGTT was calculated using the trapezoidal method (7). Shape index was calculated as glucose at $60 \mathrm{~min}$ minus glucose at $30 \mathrm{~min}$, and handled as a continuous variable in correlation analyses. A shape index $>0$ indicates the glucose curve as upward and a shape index $<0$ indicates the curve as downward. An OGTT-based insulin sensitivity (oral glucose insulin sensitivity, OGIS) was implemented on a spreadsheet according to Mari (8). We used insulinogenic index $=($ Ins 30-Ins 0)/(Glu 30-Glu 0) to estimate insulin secretion, product of OGIS and insulinogenic index to estimate the disposition index $(9,10)$.

All data are expressed as mean \pm s.D. unless otherwise indicated. The significance level was $P=0.05$. SPSS 13.0 was used for analysis. The cutoff values of IGR and diabetes mellitus were analyzed using receiver operating characteristic (ROC) curves (11). An ROC curve is a graph of sensitivity vs 1-specificity (or false-positive rate) for various cutoff definitions of a positive diagnostic test result. Sensitivity, specificity, and likelihood ratio (LR) for a positive (LR +) or negative $(\mathrm{LR}-)$ test result were calculated for various cutoffs. The LR is the ratio of the frequency of a test result in patients with disease to the frequency of the same test result in patients without disease; therefore, an LR of 1.0 reflects no diagnostic value. Area under the curve (AUC) was calculated using the SPSS ROC curve function for continuous variables. An AUC of $<0.50$ is considered worthless, $0.60-0.69$ poor, $0.70-0.79$ 
fair, 0.80-0.89 good and 0.90-1 excellent. Optimal test characteristics were considered to exist where sensitivity and specificity were maximal.

\section{Results}

The measurements of height, weight, BMI, waist to hip ratio and systolic/diastolic blood pressure were $165.5 \pm$ $7.9 \mathrm{~cm}, 70.4 \pm 15.4 \mathrm{~kg}, 25.6 \pm 4.7 \mathrm{~kg} / \mathrm{m}^{2}, 0.88 \pm 0.0 \overline{6}$, and $126 \pm 18 / 82 \pm 11 \mathrm{mmHg}$ respectively.

Using IGR as the reference, the cutoff points for IGR were $5.6,9.7,10.1,7.8$ and $6.1 \mathrm{mmol} / \mathrm{l}$ at $0,30,60$, 120 and $180 \mathrm{~min}$ respectively. Using diabetes as the reference, the cutoff points were $6.8,11.2,13,11.1$ and $7 \mathrm{mmol} / \mathrm{l}$ at $0,30,60,120$ and $180 \mathrm{~min}$ respectively. In addition, we calculated AUCg during the OGTT and determined the cutoff points for IGR and diabetes respectively using the ROC curve analysis (shown in Tables 1 and 2).

Figure 1 shows the various types of glucose and insulin curves in subjects with NGT, IGR or diabetes. The shape index and its cutoff points for IGR and diabetes are shown in Tables 1 and 2. Figure 2 shows the different profiles of glucose and insulin curves in subjects with NGT, in those classified as 1h-High7.8, in those with IGR, in those categorized as 1h-High11.1 and in subjects with diabetes.

AUCg correlated inversely with log transformed OGIS $(r=-0.64 ; P<0.001)$, the insulinogenic index $(r=-0.73 ; P<0.001)$, and the disposition index $(r=-0.80 ; P<0.001)$. There was also an inverse correlation between the shape index and OGIS $(r=-0.46 ; \quad P<0.001)$, the insulinogenic index $(r=-0.55 ; P<0.001)$, and the disposition index $(r=-0.60 ; P<0.001)$.

Table 3 summarizes the characteristics of the subjects in the category with 1h-High7.8 and of those in the category with 1h-High11.1.

\section{Discussion}

The OGTT is generally considered as more sensitive for the screening of impaired glycemia, because it detects changes in post-prandial glycemia that tend to precede changes in fasting glucose. All current diagnostic criteria for diabetes depend on a threshold value imposed on a continuous distribution of blood glucose levels. Yet, the correct glycemic threshold that discriminates 'normal' from diabetic is not obvious. Though screening for undiagnosed type 2 diabetes remains a contentious issue, there is clear evidence that once it is diagnosed, complications can be prevented in many patients $(12,13)$. The American Diabetes Association (ADA) has increasingly tightened their recommendations for detecting undiagnosed diabetes. The Expert Committee recognized an intermediate group of subjects whose glucose levels, although not meeting the criteria for diabetes, are nevertheless too high to be considered normal (2). This group is defined as having FPG levels $\geq 100 \mathrm{mg} / \mathrm{dl} \quad(5.6 \mathrm{mmol} / \mathrm{l})$, but $<126 \mathrm{mg} / \mathrm{dl}$ $(7.0 \mathrm{mmol} / \mathrm{l})$ or 2 -h values in the OGTT of $\geq 140 \mathrm{mg} / \mathrm{dl}$ ( $7.8 \mathrm{mmol} / \mathrm{l})$, but $<200 \mathrm{mg} / \mathrm{dl}(11.1 \mathrm{mmol} / \mathrm{l})$. The ADA lowered the threshold for defining IFG from $6.1 \mathrm{mmol} / \mathrm{l}$ to 5.6 in order to detect more subjects with pre-diabetes. However, to the best of our knowledge, there are no reference normal values except our previous report (4) for blood glucose values at the OGTT time points of 30 , 60 , and $180 \mathrm{~min}$. Here, we set out to analyze the reference cutoff values at these time points for both IGR and diabetes by ROC curve analysis.

We merged IFG and IGT into IGR, since patients with IFG and/or IGT were referred to as having 'pre-diabetes'. In the absence of pregnancy, IFG and IGT are not clinical entities in their own right, but rather risk factors for future diabetes as well as cardiovascular disease. They can be observed as intermediate stages in any type of diabetes. The cutoff points for IGR are similar to our previous report (4), although we recruited subjects with known diabetes for the present study, which was not the case in the previous report. This is not surprising because the ROC function is only to discriminate whether a subject is affected or unaffected when the diagnostic gold standard is set right. Although data from some cross-sectional studies suggest that insulin sensitivity (14-16) and $\beta$-cell function (17-19) decrease as a function of age, in our previous report (4) and other studies (19-22), age was not found to be an independent determinant of either insulin sensitivity

Table 1 The blood glucose cutoff values, area under curve (AUC), 95\% confidence interval (Cl), sensitivity (Se), specificity (Sp), likelihood ratio for positive test $(\mathrm{L}+)$ and likelihood ratio for negative test $(\mathrm{L}-)$ of different time points of the orgal glucose tolerance test, area under the curve of glucose (AUCg) and shape index in relation to impaired glucose regulation. Values derived from ROC analysis.

\begin{tabular}{|c|c|c|c|c|c|c|c|}
\hline Time (min) & Cutoff (mmol/l) & $A U C \pm$ s.E.M. & $\mathrm{Cl}$ & $\mathrm{Se}(\%)$ & Sp (\%) & LR+ & LR- \\
\hline 0 & 5.6 & $0.953 \pm 0.004$ & $0.945-0.960$ & 88.68 & 100 & $+\infty$ & 0.1132 \\
\hline 30 & 9.7 & $0.883 \pm 0.006$ & $0.871-0.895$ & 77.49 & 83.85 & 4.7968 & 0.2685 \\
\hline 60 & 10.1 & $0.930 \pm 0.005$ & $0.921-0.939$ & 83.72 & 86.11 & 6.0291 & 0.1891 \\
\hline 120 & 7.8 & $0.943 \pm 0.004$ & $0.935-0.951$ & 83.34 & 100 & $+\infty$ & 0.1666 \\
\hline 180 & 6.1 & $0.851 \pm 0.007$ & $0.838-0.865$ & 64.62 & 94.26 & 11.2565 & 0.3753 \\
\hline AUCg & 24 & $0.963 \pm 0.003$ & $0.957-0.969$ & 85.63 & 95.46 & 18.8647 & 0.1505 \\
\hline Shape index & 1.3 & $0.844 \pm 0.007$ & $0.830-0.859$ & 68.74 & 89.85 & 6.7746 & 0.3479 \\
\hline
\end{tabular}


Table 2 The blood glucose cutoff values, area under curve (AUC), 95\% confidence interval (Cl), sensitivity (Se), specificity (Sp), likelihood ratio for positive test $(\mathrm{L}+)$ and likelihood of negative test $(\mathrm{L}-)$ of different time points of the oral glucose tolerance test, area under the curve of glucose (AUCg) and shape index in relation to diabetes. Values derived from ROC analysis.

\begin{tabular}{|c|c|c|c|c|c|c|c|}
\hline Time (min) & Cutoff $(\mathrm{mmol} / \mathrm{l})$ & $A U C \pm$ S.E.M. & $\mathrm{Cl}$ & $\mathrm{Se}(\%)$ & Sp (\%) & LR + & LR - \\
\hline 0 & 6.8 & $0.955 \pm 0.004$ & $0.947-0.963$ & 83.27 & 96.49 & 23.7385 & 0.1734 \\
\hline 30 & 11.2 & $0.886 \pm 0.006$ & $0.874-0.898$ & 78.35 & 84.68 & 5.1132 & 0.2557 \\
\hline 60 & 13.0 & $0.952 \pm 0.004$ & $0.945-0.959$ & 85.73 & 89.6 & 8.2428 & 0.1593 \\
\hline 120 & 11.1 & $0.977 \pm 0.003$ & $0.972-0.983$ & 89.93 & 100 & $+\infty$ & 0.1007 \\
\hline 180 & 7.0 & $0.940 \pm 0.005$ & $0.930-0.949$ & 83.66 & 92.68 & 11.4247 & 0.1763 \\
\hline AUCg & 30.9 & $0.985 \pm 0.002$ & $0.982-0.989$ & 91.51 & 96.25 & 24.3789 & 0.0882 \\
\hline Shape index & 2.0 & $0.893 \pm 0.006$ & $0.881-0.905$ & 78.75 & 84.25 & 4.9986 & 0.2523 \\
\hline
\end{tabular}

or $\beta$-cell function. Accordingly, we have not used age stratification in the present analyses.

There are three different time point cutoff values other than fasting and 2-h PG, which may induce confusion when interpreting the cutoff values. Therefore, we calculated the AUCg during OGTT, assuming that the AUCg may include most of the information on glucose metabolism. Once more, we analyzed the cutoff values ( 24 and $30.9 \mathrm{mmol} / \mathrm{l}$ respectively) for both IGR and diabetes.

Figure 1A shows that the glucose curves of subjects with NGT, IGR or diabetes are very different, suggesting that the shape includes metabolic information not captured by the level of glycemia alone. We made an attempt to extract metabolic information from the shape of the PG curve by calculating the shape index and its cutoff values (shown in Tables 1 and 2). The shape index may reflect the early insulin secretion during the first hour. Accordingly, it may be useful for estimating the $\beta$-cell function.

After logarithmic transformation of the OGIS, the insulinogenic index, and the disposition index, we observed an inverse correlation between these parameters and both AUCg and the shape index. During the development of insulin resistance, the insulin secretion is usually increased. As long as the compensation is adequate, the disposition index remains normal and the glucose tolerance is normal; but the finding that the correlation coefficients of AUCg and shape index to the disposition index tended to be higher than those observed for the OGIS and the insulinogenic index supports the critical and fundamental importance of $\beta$-cell dysfunction in the development of type 2 diabetes. When the increase in insulin secretion becomes inadequate in relation to insulin resistance, glucose intolerance, and type 2 diabetes emerge.

As for the simultaneous assessment of both insulin secretion and sensitivity, however, a great deal of attention must be placed on the choice of the experimental tests to be performed (23). The most important issue is that the two measurements must be as independent as possible. This may yield some problems, when the disposition index has to be determined in large epidemiological studies. For instance, a widely used method to assess insulin
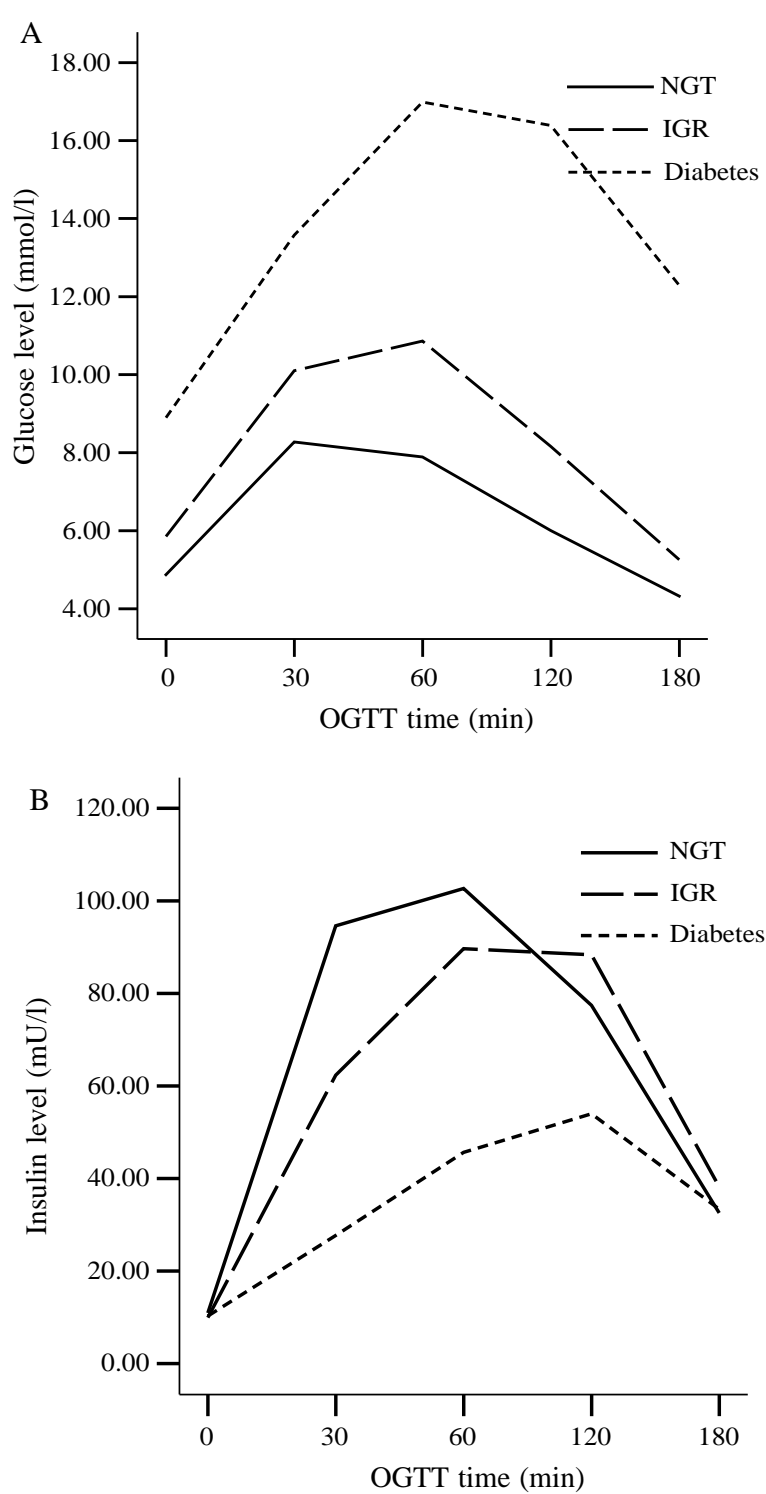

Figure 1 The glucose $(A)$ and insulin (B) profiles during OGTT in subjects with NGT, IGR, or diabetes. 

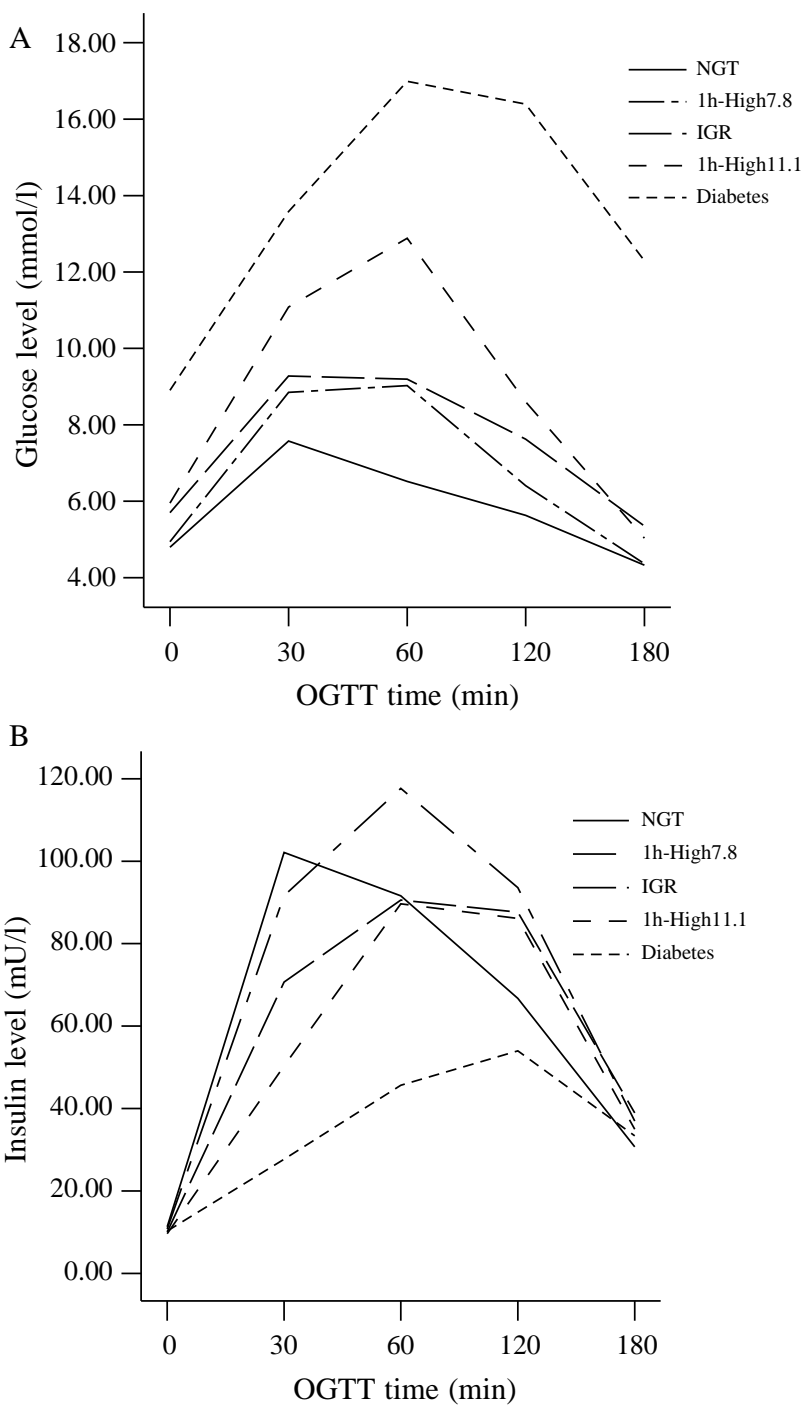

Figure 2 The glucose (A) and insulin (B) profiles during OGTT in subjects with NGT, 1h-High7.8, IGR, 1h-High11.1 or diabetes.

sensitivity is HOMA, because it uses only the product of fasting insulin and glucose concentration. The corresponding index of $\beta$-cell function also uses basal insulin; thus, the two indices are strictly interrelated both being proportional to the same basal insulin measurement. Their product, therefore, does not make much sense and should not be used. To have a valid measurement of insulin secretion, it is also necessary in large studies to use dynamic tests, such as the OGTT, which provide independent measurements of $\beta$-cell function, for example, from the insulinogenic index (24). For calculating the disposition index, model-based indices such as OGIS $(8,9)$ may not be related to specific insulin variables and thus the disposition index reproduces the relationship between insulin sensitivity and $\beta$-cell function more realistically. However, these formulae used in our study should be viewed critically, because none of the OGTT indices reveals exactly the same information as those obtained during hyperinsulinemic euglycemic clamps and hyperglycemic clamps. Thus, the results must be interpreted cautiously bearing in mind all the assumptions and simplifications built in these indices.

Similarly to Alzaid et al. (25), we noted that a large proportion of the subjects screened had a very interesting glucose profile as follows: (i) while the fasting and 2-h PG concentrations were below the IFG and/or IGT, the 1-h glucose concentration was by contrast above $7.8 \mathrm{mmol} / \mathrm{l}$ and (ii) while the fasting and 2-h PG concentrations were below the diabetic threshold, the 1-h glucose concentration was in contrast strikingly abnormal $(\geq 11.1 \mathrm{mmol} / \mathrm{l})$. Neither the current WHO nor the ADA criteria consider the 1-h blood glucose levels. Is it clinically justifiable to disregard post-prandial hyperglycemia (in some cases, the 1 -h glucose as high as $18 \mathrm{mmol} / \mathrm{l}$ ), just because it did not fall at the 'official' 2-h time point of the OGTT? We are the first to propose the concept of isolated 1-h hyperglycemia (defined in Subjects and Methods as $1 \mathrm{~h}$ High7.8 and 1h-High11.1) and to describe their characteristics. Conceptually, 30-60 min after the ingestion of a meal, not several hours afterwards, represents the peak point of metabolic and digestive events and therefore, potentially is a better time to choose for the detection of the earliest signs of metabolic dysfunction. Moreover, in temporal terms at least, what happens at 1-h is bound to affect the 2-h glucose concentration (spillover effect) and not vice versa.

Table 3 Cases with abnormal 1-h glucose values (1h-High7.8 and 1h-High11.1).

\begin{tabular}{|c|c|c|c|}
\hline & $\begin{array}{c}\text { OGTTO }<5.6 \& \text { OGTT120 }<7.8 \\
\& \text { OGTT60 }>7.8\end{array}$ & & $\begin{array}{c}\text { OGTTO }<7 \& \text { OGTT120 }<11.1 \\
\& \text { OGTT60 } \geq 11.1\end{array}$ \\
\hline Total & $354 / 2886(12.3 \%)$ & Total & $434 / 2886(15.0 \%)$ \\
\hline OGTT $60 \geq 10.1$ & $104 / 354(29.4 \%)$ & OGTT $60 \geq 13$ & $169 / 434(38.9 \%)$ \\
\hline Shape index $\geq 1.3$ & $78 / 354(22.0 \%)$ & Shape index $\geq 2.0$ & $205 / 434(47.2 \%)$ \\
\hline$A \cup C g \geq 24$ & $34 / 354(9.6 \%)$ & $A \cup C g \geq 30.9$ & $61 / 434(14.1 \%)$ \\
\hline $\begin{array}{l}\text { OGTT60 } \geq 10.1 \& \text { Shape } \\
\text { index } \geq 1.3\end{array}$ & $45 / 354(12.7 \%)$ & OGTT60 $\geq 13$ \& Shape index $\geq 2.0$ & $114 / 434(26.3 \%)$ \\
\hline OGTT60 $\geq 10.1 \&$ AUCg $\geq 24$ & $32 / 354(9.0 \%)$ & OGTT60 $\geq 13 \&$ AUCg $\geq 30.9$ & $59 / 434(13.6 \%)$ \\
\hline$A \cup C g \geq 24$ \& Shape index $\geq 1.3$ & $17 / 354(4.8 \%)$ & $A U C g \geq 30.9$ \& Shape index $\geq 2.0$ & $39 / 434(9.0 \%)$ \\
\hline $\begin{array}{l}\text { AUCg } \geq 24 \& \text { Shape index } \geq 1.3 \\
\quad \& \text { OGTT } 60 \geq 10.1\end{array}$ & $17 / 354(4.8 \%)$ & $\begin{array}{l}\text { AUCg } \geq 30.9 \text { \& Shape index } \geq 2.0 \\
\text { \& OGTT } 60 \geq 13\end{array}$ & $39 / 434(9.0 \%)$ \\
\hline
\end{tabular}


Obviously, one way to determine the significance of the 1-h glucose concentration would be to study these subjects prospectively to determine the natural history of the glucose abnormality in relation to the development of diabetic complications. While the prospective study is in progress, this phenomenon can be analyzed using our cutoff values as shown in Table 3. Figures 1 and 2 indicate that the profiles of glucose and insulin of the subjects categorized as $1 \mathrm{~h}$ High7.8 and 1h-High11.1 are very different from those seen in subjects with NGT and IGR. The glucose profile in subjects with $1 \mathrm{~h}$-High7.8 is similar to that seen in those with IGR, while the glucose curve of the persons with 1h-High11.1 is conspicuously higher than that of subjects with IGR. Figure 1B shows that the compensation of increased insulin secretion in IGR is not obvious. This is similar to observations in the Japanese population but different from Caucasians (26), which may be due to ethnic differences. When the subjects with $1 \mathrm{~h}$-High7.8 and those with 1hHigh11.1 were separated, we can see increased insulin secretion in the 1h-High7.8, which most likely compensates for the insulin resistance to keep the 2-h PG below $7.8 \mathrm{mmol} / \mathrm{l}$. Accordingly, the $1 \mathrm{~h}$-High subjects, who can only be identified by accessing the 1-h PG, are definitely different from subjects with NGT or IGR. Attention should be paid to such subjects, before they fall into the pre-diabetes and diabetes criteria of WHO and ADA.

One drawback of our study is that we performed the OGTT only once in each subject. Our study comprised only Chinese subjects, and it remains to be established whether these results apply also to other ethnic groups. Therefore, we do not propose at this point to use the cutoff values defined for different time points of OGTT, for AUCg, and for the shape index to diagnose IGR and diabetes. We wish to wait for the outcome of the prospective study before making any definite recommendation. We conclude that the measurement of blood glucose levels during an OGTT at time points other than at 0 and 120 min provides an additional valuable information on the glucose metabolism, and therefore we encourage other investigators to test the value of, e.g. 1-h PG concentrations obtained during an OGTT.

\section{Acknowledgements}

This study was supported by the National Nature Science Foundation of China (No. 30470817) and F Hoffmann-La Roche Ltd. We thank Jian Yang, Wenzhong Zhou, Di Zhang, Youping Liu, Jiping Li, Lu $\mathrm{Yu}$, Junfeng Han, Weibin Xu, Weixia Jian, Jingyan Tian for collecting all the data.

\section{References}

1 World Health Organization Department of Noncommunicable Disease Surveillance. Definition, diagnosis and classification of diabetes mellitus and its complications; Part 1: diagnosis and classification of diabetes mellitus. 1999.

2 American Diabetes Association. Diagnosis and classification of diabetes mellitus. Diabetes Care 200528 s37-s42.

3 The expert committee on the diagnosis and classification of diabetes mellitus. Follow- up report on the diagnosis of diabetes mellitus. Diabetes Care 200326 3160-3167.

4 Zhou W, Li H, Gu Y, Yu L, Han J, Xu W, Jian W, Tian J, Zhou W, Zhang D, Liu Y, Yang J, Li J, Li G \& Luo M. The ROC analysis for different time points during oral glucose tolerance test. Diabetes Research and Clinical Practice 200672 88-92.

5 Fuchigami M, Nakano H, Oba K \& Metori S. Oral glucose tolerance test using a continuous blood sampling technique for analysis of the blood glucose curve. Nippon Ronen Igakkai Zasshi, Japanese Journal of Geriatrics (Tokyo) 199431 518-524.

6 Tschritter O, Machicao F, Fritsche A, Haring H, Shirkavand F \& Stumvoll M. Assessing the shape of the glucose curve during an oral glucose tolerance test. Diabetes Care 200326 1026-1033.

7 Purves RD. Optimum numerical integration methods for estimation of area-under- the- curve (AUC) and area- under- the- momentcurve (AUMC). Journal of Pharmacokinetics and Biopharmaceutics 1992 20 211-227.

8 Mari A, Pacini G, Murphy E, Ludvik B \& Nolan JJ. A model-based method for assessing insulin sensitivity from the oral glucose tolerance test. Diabetes Care 200124 539-548.

9 Rask E, Olsson T, Soderberg S, Holst JJ, Tura A, Pacini G \& Ahren B. Insulin secretion and incretin hormones after oral glucose in nonobese subjects with impaired glucose tolerance. Metabolism 2004 53 624-631.

10 Pacini G \& Ahren B. Importance of quantifying insulin secretion in relation to insulin sensitivity to accurately assess beta cell function in clinical studies. European Journal of Endocrinology 2004150 97-104.

11 Hanley JA \& McNeil BJ. A method of comparing the areas under receiver operating characteristic curves derived from the same cases. Radiology 1983148 839-843.

12 UK Prospective Diabetes Study Group. Intensive blood glucose control with sulphonylureas or insulin compared with conventional therapy and risk of complications in patients with Type 2 diabetes mellitus-UKPDS 33. Lancet 1998352 837-853.

13 UK Prospective Diabetes Study Group. Tight blood pressure control and risk of macrovascular and microvascular complications in Type 2 diabetes mellitus. UKPDS 38. British Medical Journal 1998317 703-712.

14 DeFronzo RA. Glucose intolerance and aging. Diabetes Care 1981 4 493-501.

15 Rowe JW, Minaker KL, Pallotta JA \& Flier JS. Characterization of the insulin resistance of aging. Journal of Clinical Investigation 1983 71 1581-1587.

16 Elahi D, Muller DC, McAloon-Dyke M, Tobin JD \& Andres R. The effect of age on insulin response and glucose utilization during four hyperglycemic plateaus. Experimental Gerontology 199328 393-409.

17 Chen M, Bergman RN, Pacini G \& Porte D Jr. Pathogenesis of agerelated glucose. intolerance in man: insulin resistance and decreased beta-cell function. Journal of Clinical Endocrinology and Metabolism 198560 13-20.

18 Muller DC, Elahi D, Tobin JD \& Andres R. The effect of age on insulin resistanceand secretion: a review. Seminars in Nephrology $199616289-298$.

19 Pacini G, Valerio A, Beccaro F, Nosadini R, Cobelli C \& Crepaldi G. Insulin sensitivity and beta-cell responsivity are not decreased in elderly subjects with normal OGTT. Journal of the American Geriatrics Society 198836 317-323. 
20 Broughton DL, James OW, Alberti KG \& Taylor R. Peripheral and hepatic insulin sensitivity in healthy elderly human subjects. European Journal of Clinical Investigation 199121 13-21.

21 Ferrannini E, Vichi S, Beck-Nielsen H, Laakso M, Paolisso G \& Smith U. Insulin action and age, European Group for the Study of Insulin Resistance (EGIR). Diabetes 199645 947-953.

22 Stumvoll M, Yki-Jarvinen H, Mitrakou A, Haeften TV, Pimenta W, Renn W, Jenssen T \& Gerich J. Use of the oral glucose tolerance test to assess insulin release and insulin sensitivity. Diabetes Care 2000 23 295-301.

23 Pacini G \& Mari A. Methods for clinical assessment of insulin sensitivity and beta- cell function. Best Practice in Research and Clinical Endocrinology and Metabolism 200317 305-322.

24 Phillips DI, Clark PM, Hales CN \& Osmond C. Understanding oral glucose tolerance: comparison of glucose or insulin measurements during the oral glucose tolerance test with specific measurements of insulin resistance and insulinsecretion. Diabetic Medicine 199411 286-292.

25 Alzaid AA \& Sobki S. The diagnosis of diabetes mellitus. A contest between 2 points! Saudi Medical Journal 200122 839-842.

26 Fukushima M, Suzuki H \& Seino Y. Insulin secretion capacity in the development from normal glucose tolerance to type 2 diabetes. Diabetes Research and Clinical Practice 2004 66S s37-s43.

Received 2 February 2006

Accepted 28 April 2006 